\title{
Artefato visual: uniforme escolar
}

\author{
Teresinba Vilela \\ Victor Junger
}

Universidade do Estado do Rio de Janeiro

\section{Resumo}

Este texto pretende trazer para discussão o uniforme escolar como artefato visual, a partir principalmente de uma experiência vivenciada por um dos autores em uma escola do Ensino Básico. Refletimos sobre o uniforme escolar e sua estreita relação com as estratégias disciplinares/institucionais (FOUCAULT, 2004). Trazemos para conversa o Queer (DIAS, 2012; PINAR, 2007) como possibilidade de se pensar este corpo estranho, corpo que produz estranhamentos nas experiências cotidianas e que, inevitavelmente, recusa os ordenamentos funcionais assim cristalizados. A premissa desinvibilizadora que este texto procura fortalecer, se propõe a elucidar a potência epistêmica concentrada principalmente na interface entre ensino de arte e os espaços/tempos da escola.

Palavras-chave: ensino de arte; cotidiano escolar; visualidade

\section{Abstract}

This text aims to bring to discussion the school uniform as a visual artifact, based mainly on an experience lived by one of the authors in a school of basic education. We reflect on the school uniform and his close relationship with the disciplinary/institutional strategies (Foucault, 2004). We also bring to the conversation the Queer (DIAS, 2012; PINAR, 2007) as a possibility to think about this strange body, the body that produces strangeness in everyday experiences and, inevitably, refuses the functional orders well crystallized. The disinvisibility premise, that this text seeks to strengthen, aims to elucidate the epistemic power concentrated mainly on the interface between art education and school space/time.

Keywords: art education, school everyday lives; visuality. 
O uniforme escolar denominado também como farda ou fardamento é um artefato próprio aos cotidianos escolares, sendo, para os estudos da cultura visual, um instigante artefato visual que inevitavelmente fez, faz ou fará parte de nossas vidas. Para Duncun (2003), os artefatos visuais podem ser os mais variados como também ressalta Porres (2013), a relevância de seu estudo está na experiência cotidiana que os sujeitos podem ter com esses artefatos. Os estudos da cultura visual (HERNÁNDEZ, 2007) corroboram para reconstrução das nossas referências, da forma como olhamos e somos olhados. Da mesma forma que para Porres (2013, p.158), do modo como vizualizam, como somos vizualizados e o efeito da visualidade sobre as subjetividades possíveis. Aqui pensamos e perguntamos como o uniforme escolar como artefato visual vem nos construindo como sujeitos.

Nesse sentido, propomos uma reflexão crítica do que eles suscitam para além de suas cores, formas e modelos. Neste estudo, temos como tempo e espaço de interesse a Escola Básica, o Ensino Fundamental, principalmente por nessa modalidade ser exigido o uso do uniforme pela maioria das escolas. Ademais, todos os aspectos culturais que constituem as vidas nas escolas interessam às pesquisas que desenvolvemos no Grupo de Pesquisa Estudos Culturais em Educação e Arte ${ }^{1}$.

Tendo esta reflexão como pano de fundo, este trabalho foi pensado a partir de uma experiência vivenciada por um de seus autores, professora de artes dos anos finais do Ensino Fundamental, de tal modo desconcertante, e não menos instigadora, a ponto de nos lançar a problematizações engendradas nas e pelas margens dos currículos prescritos, ou seja, para além de toda a ortodoxia responsável por resguardar um espaço próprio ao ensino de arte. Como será possível ver a seguir, sob a aparente tentativa de customizar o uniforme escolar, um de seus alunos foi repreendido pela escola de forma vexatória a contrapelo dos princípios que regeriam a Formação que cabe à Educação Formal, no momento em que, sem o perceber, ele subvertia as lógicas que arbitrariamente mantém o dispositivo institucional. Nesse sentido, este texto se configura como uma quase conversa entre os autores, na qual são alinhavados o vivido nos espaços/tempos escolares e elementos teóricos outros que nos ajudariam a elucidar a potência epistêmica destas experiências.

Raimundo Martins (2005), em um de seus estudos, afirma a cultura visual como mediadora favorável ao deslocamento entre o empírico e o conceitual, em que ambas as experiências devem oferecer uma relação, isto é, o que ele chama de processos de conversão do conceitual em experiência ou da experiência em conceitos (MARTINS, 2005, p.142).

Assim, a cotidianidade pode ser tomada em sua usinagem imaginal e suas fabricações imagéticas, onde se encontram expostas as mutabilidades dos fluxos e as potencialidades do imaginário (VICTORIO FILHO, 2005), constituindo, dessa maneira, os es-

$\infty<\infty<\infty<\infty<\infty<\infty \times \infty \times \infty \times \infty \times \infty \times \infty \times \infty$

1 Grupo de Pesquisa Estudos Culturais em Educação e Arte - UFRRJ/UERJ 
paços/tempos da Escola e, principalmente, a cultura visual que lhe é própria (CERTEAU, 1998). Este texto, longe de se reduzir conceitualmente o seu universo imaginal, procura incitar desdobramentos reflexivos, sem necessariamente ser conduzido a um viés funcionalista, que, em última instância, destinaria à inexistência/invisibilidade uma imensa profusão de experiências estéticas.

Nesta discussão, tomamos o uniforme como um componente emblemático da cultura visual da escola, bem como um artefato que pode ser problematizado (NASCIMENTO, 2013) para se repensar algumas práticas educacionais. Posto que atravessado pela multiplicidade de relações que constitui a escola, o uniforme não se encontraria dissociado dos currículos ocultos que emanam na/da cotidianidade, nem mesmo destituídos de qualquer relação para com os currículos prescritos da instituição. Buscamos pensar o que acontece por entre as margens do componente curricular, ou seja, nas fronteiras do ensino de arte, partindo do solo sobre o qual são efetuadas as aprendizagens cotidianas, solos os quais, a despeito de inexorável concretude, são dissipados pela matéria brumosa (mas nada leve) dos currículos oficiais.

Tal deslocamento intenta não limitar este texto aos arranjos do visível autorizados pelo institucional, bem como à limitada compreensão sobre o sistema de arte a que se encontra sujeito o ensino de arte (VICTORIO FILHO, 2012), visto que, neste último caso, as práticas de fruição e as experiências estéticas são intensiva e ostensivamente assediadas por uma lógica mercadologizante e, portanto, passíveis de sofrer um processo de recodificação sobre o prisma da produção/consumo. Desse modo, sem obliterar os referentes evocados pela experiência, nossos esforços se voltam de imediato para as linhas de fuga agenciadas sobre e a partir do elemento tipicamente escolar, em questão, o uniforme e o que ele originalmente instaura. Convém observar que o que porta corpo assume lógicas performáticas e, via de regra, estetizadas sob quaisquer imposições institucionais e, sobretudo, se aceitarmos que cada prática de cada praticante compõe anônima o coletivo, mas, fulgura, discretamente ou não, a sua singularidade.

Ao recorrer primeiramente à nossa memória escolar, percebemos que nela habitam alguns uniformes e, nesta tentativa de recuperar seus detalhes, é o corte e o tecido que de início advém a esta conversa. Um dos autores, quando ainda estudava na escola pública, recorda-se do momento em que a calça de tergal ${ }^{2}$ azul pôde ser substituída por uma de brim ${ }^{3}$ azul marinho. A cor azul marinho e branco predominou no período em que ela estudou com poucas variações no modelo da calça, da saia ou da blusa. De certa

$\infty<\infty<\infty<\infty<\infty<\infty<\infty<\infty<\infty<\infty<\infty<\infty$

2 Tergal: "O Tergal, também chamado de Dácron (Inglaterra, Itália e Espanha) e Terylene (Alemanha), é um tecido produzido com fios puros ou mistos de poliéster podendo ser também misturado com algodão". Disponível em: < http://www.portaisdamoda.com.br/glossario-moda tecido+tergal.htm > Acesso em 06 abr. 2013.

3 Brim: "Tecido de algodão originalmente produzido pela cidade de Nímes. Sua ligação é feita em estrias diagonais (sarja), cujo ligamento produz, frequentemente, um tecido mais resistente que o ligamento tela". Disponível em: < http://www.portaisdamoda.com.br/glossario-moda tecido+tergal.htm> Acesso em 06 abr. 2013. 
forma, infelizmente, parecemos não guardar boas recordações dos uniformes escolares, entretanto, ainda mais significativo é a narrativa de um dos autores, no sentido e que, por justamente deflagrar os ordenamentos sobre o seu uso, teria nos incentivado a escrever este texto.

Numa Escola Básica do Rio de Janeiro, há alguns anos atrás, os alunos "receberam" um modelo novo de uniforme. Em casa, um dos alunos cortou um pouco as mangas da camisa de malha e, no dia seguinte, foi para escola vestindo-a. Certamente ele quisesse customizar sua camisa, isto é, personalizá-la e diferenciá-la, o que seria uma atitude contrária à ideia tradicional do uniformizar.

Esse aluno se destacava na sua turma, pois, modelava sua sobrancelha, utilizava acessórios pelo corpo, suas unhas eram todas compridas, seus cabelos sempre muito bem arrumados. Na aula de artes seus desenhos se sobressaiam, apresentando uma produção intensa, com traços bastante peculiares, isto é, alguns alunos afinal não precisavam nomear seus trabalhos, pois suas produções os identificam. De todo o modo, ao chegar à escola com sua camisa customizada, esse aluno foi repreendido, sua camisa passou de sala em sala, vestida em um boneco. E, como se não bastasse, o boneco ficou pendurado por algumas horas na parte interna da escola.

Esse boneco pode nos reportar a outras imagens de punição, exclusão - como um boneco de Judas ${ }^{4}$ malhado nas ruas no Sábado de Aleluia da Semana Santa ou a imagem de Tiradentes. E ainda a um espantalho ${ }^{5}$ no meio da plantação para afugentar os pássaros. Mais especificamente, nesse caso, afugentar os que seguissem o mesmo exemplo. Esse relato possui uma íntima relação com o que Michel Foucault (2004) designa por relação de dominação, onde não é o artefato camisa, mas a relação de poder e controle sobre o corpo que parece emergir em toda esta dinâmica, a despeito ou porque o corpo transborda toda a represa representativa que lhe seja imposta (VICTORIO FILHO, p. 151, 2012). Após o acontecido, o aluno não retornou à escola.

Assim, diante das reflexões que propomos a partir do artefato visual uniforme escolar, nossa atenção se voltou para acontecimento e para a violência mobilizada pela instituição a fim de elucidar/pensar os agenciamentos que emergiram nos cotidianos da escola, sem com isso perder de vista a complexidade própria ao acontecimento. E, para tanto, retomamos Michel Foucault como ponto de partida e alerta acerca das reflexões que parecem se desdobrar tendo como fundo esta experiência:

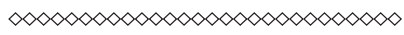

4 Segundo Felipe França: "Malhação de Judas ou Queima de Judas é uma tradição vigente em diversas comunidades católicas e ortodoxas que foi introduzida na América Latina pelos espanhóis e portugueses. É também realizada em diversos outros países, sempre no Sábado de Aleluia, simbolizando a morte de Judas Iscariotes". Disponível em: $<$ http://www.tribunadolitoralpb.com.br/2011/04/tradicao-do-boneco-de-judas-em-rio.html $>$. Acesso em 18 fev. 2013.

5 Manuel Paula Maça explica: "A função essencial do espantalho, como o nome indica, seria "espantar" ou "meter medo". No Latim Clássico de Cícero seria "expaver", o que, no Latim popular terá dado 'expaventar. Daqui ao termo espantalho, um salto linguístico de que o tempo e as gerações se terão encarregado". Disponível em: <http://carreiradomato.blogspot.com.br/2009/02/espantalho-um-velho-deus-em-deceadencia. html>. Acesso em: 18 fev. 2013. 
$\mathrm{Na}$ oficina, na escola, no exército funciona como repressora toda uma micropenalidade do tempo (atrasos, ausências, interrupções das tarefas), da atividade (desatenção, negligencia, falta de zelo), da maneira de ser (grosseria, desobediência), dos discursos (tagarelice, insolência), do corpo (atitudes "in-corretas", gestos não conformes, sujeira), da sexualidade (imodéstia, indecência). Ao mesmo tempo e utilizada, a titulo de punição, toda uma serie de processos sutis, que vão do castigo físico leve a privações ligeiras e a pequenas humilhações. Trata-se ao mesmo tempo de tornar penalizáveis as frações mais tênues da conduta, e de dar uma função punitiva aos elementos aparentemente indiferentes do aparelho disciplinar: levando ao extremo, que tudo possa servir para punir a mínima coisa; que cada indivíduo se encontre preso numa universalidade punível-punidora. (FOUCAULT, 2004, p.148)

A partir dessas considerações, fundados na experiência relatada, somos tentados a interrogar de que modo o uniforme participa da cultura visual que permeia a escola, ou ainda, que seja própria ao escolar. Em outras palavras, de que modo se dá a sua participação no funcionamento da instituição escolar, como a visualidade instaurada por ele toma parte no exercício do poder disciplinar, e como os efeitos de poder são frequentemente evocados em seus usos.

Ao nos perguntarmos sobre o uniforme escolar e sua estreita relação com as estratégias disciplinares, acreditamos fundamentalmente que o exercício do poder e o encaixamento das vigilâncias hierarquizadas (FOUCAULT, 2004, p.144), no que tange à produção de uma dada visualidade, não se encontrariam limitados aos efeitos da arquitetura institucional. É, afinal, correlativa à construção de seus edifícios a indumentária que vestirá os internos: ou seja, a instituição não simplesmente funda para si um lugar próprio (CERTEAU, 1998), como igualmente fornece os códigos visuais que, em última instância, tornariam legíveis os corpos. Isto é, o corpo dos internos é dado a ver sob uma modalidade visual ratificadora e coerente com funcionamento institucional.

Não é o triunfo, é a revista, é a 'parada', forma faustosa do exame. Os 'súditos' são aí oferecidos como 'objetos' à observação de um poder que só se manifesta pelo olhar. Não recebem diretamente a imagem do poderio soberano; apenas mostram seus efeitos - e por assim dizer em baixo relevo - sobre seus corpos tornados exatamente legíveis e dóceis. (FOUCAULT, 2004, p.156).

Os dispositivos de poder são constituídos e constituem campos de visibilidade, maquinaria de fazer ver e sentir, que difratam o visível e o invisível produzindo, por esbatimento da luz, regiões claras e zonas de opacidade. Se os dispositivos configuram 
quadros do visível, isso ocorre em estreita correlação com linhas de enunciação, curvas do dizível, ditos e não-ditos das redes, que terminam por infiltrar e ser infiltrados pelos campos de visibilidade. Inscritos nas relações de poder, os dispositivos respondem estrategicamente a pontos de singularidade e focos de resistência, mobilizando uma multiplicidade de redes responsáveis por alinhavar os diferentes elementos que os compõem.

A particularidade dos dispositivos disciplinares é ser uma máquina óptica para ver sem ser visto (DELEUZE, 2012, p. 01). O centro ocular da prisão turva a sua torre, ao passo que as células periféricas sofrem com o esbatimento de luz: os prisioneiros seriam vistos sem ver; o observador veria tudo sem ser visto. Os dispositivos disciplinares, nesse sentido, almejam uma dupla invisibilidade: é preciso que esta maquinaria perca seus contornos, dilua suas linhas, ganhe em imprecisão; por outro lado, é o próprio processo disciplinar que, ao instaurar a norma, produz regiões de invisibilidade: o segredo, para ele (o poder), não é da ordem do abuso; é indispensável ao seu funcionamento (FOUCAULT, 1979, p. 83).

É preciso ter em mente, entretanto, que toda visibilidade se produz insidiosamente em relação a uma dada invisibilidade, sendo-lhe constitutiva e, principalmente, intrínseca; assim como a invisibilidade não prescinde de certa visibilidade, que ela mesma comporta e que a torna possível. Antes, pensamos em processos estratégicos que, por meio de um regime enunciativo do estético, somente ganham eficácia quando a instituição ora acentua demasiadamente seus investimentos sobre a visibilização de seus componentes, ora esforça-se por invisibilizar sem interrupções os procedimentos disciplinares. O regime enunciativo, nesse sentido, garante um modo de aceitabilidade da visualidade institucional/disciplinar: o poder, como puro limite traçado à liberdade, pelo menos em nossa sociedade, é a forma geral de sua aceitabilidade (FOUCAULT, 1979, p. 83).

O uniforme escolar, desse modo, ofereceria os códigos necessários a esta maquinaria escópica, onde a visibilidade dos internos equivaleria, em parte, à visibilidade dos processos responsáveis pela docilização dos corpos: a estampa da indumentária inevitavelmente expõe a eficácia dos rudimentos institucionais. O seu apresso pelo rigor, que se confunde frequentemente com o asseio e a higiene, pode ser então apreendido pelo tratamento destinado pela instituição ao uniforme escolar: não somente como um instrumento que distingue os corpos dos internos em um campo de visibilidade, não somente um fazer ver por entre as instalações da escola, mas, em muitos casos, um artefato capaz de ostentar signos de distinção social.

As gravatas e abotoaduras surgem como correlatos da vida adulta por meio dos quais parece ser antecipada a passagem dos educandos pelos ritos socialmente outorgados; manchas e rasgões devem ser evitados como forma de preservar a aparência do ambiente escolar. Sapatos que ainda denotam a procedência social do interno; bem como toda uma estética não sujeita às oscilações da moda e que, ao mesmo tempo, não represente um perigo à ordem e ao decoro no interior da escola (SILVA, 2006, p. 73). Ou seja, o uniforme escolar não cessou de ser pensado/concebido pela instituição em torno das possibilidades funcionais por ele oferecidas. 
As marcas da escolarização, nesse sentido, configuram a indumentária a partir de uma discursividade que faz ver o educando nos modos pelos quais uma dada sociedade conduz o ensino, assim como o faz ser socialmente conduzido pelos investimentos que a ele destina. Em síntese, veste-se o corpo a fim de se fazer ver os internos dentro da arquitetura da instituição; vestem-se, por sua vez, os internos como forma de portar os emblemas da consagração social.

Ademais, conforme o corpo passa a ser ornado pelos códigos institucionais, ele termina por recobrir sob uma camada homogeneizante a diferença que lhe é intrínseca. Se a univocidade relacional do olhar único (olhar disciplinar) reduz tudo a uma lógica binária, o pulsar diferenciante do corpo se encontra coagido à exterioridade deste sistema de valências. Ele então se vê permanentemente deslocado, assujeitado pelo institucional, amputado na diferença que o constitui e o destina a sua organicidade.

Nos espaços de poder, o uniforme apaga os referentes singulares do corpo em prol de uma lógica que favoreça o ordenamento disciplinar. E assim o faz ao reduzir a um mero desvio da normalidade qualquer manifestação que escape ao prescrito. A visualidade imposta pelo uniforme, ao compor o cenário escolar como uma camada homogeneizadora, também permite a fácil identificação e captura dos elementos diferenciantes que ensejam a livre afirmação de sua singularidade. Tais manifestações são tidas frequentemente como verdadeiras ameaças já que, de certo modo, elas equivalem à aparente demolição do edifício disciplinar e, com ele, o risco de perder toda a funcionalidade das relações.

Entretanto, mesmo submetido à lógica binária, o uniforme paradoxalmente torna possível o fissuramento da disciplinaridade, na medida em que deve operar inexoravelmente no plano das micrológicas ordinárias e, por conseguinte, no limiar subversivo dos usos. Estratégia que, ao nascer, expõe o germe de seu próprio aniquilamento. A esta altura, é importante enfatizar que a multiplicidade dos fazeres e usos insidiosamente promovem abalos táticos na univocidade lógica dos lugares próprios (CERTEAU, 1998) e, desse modo, a escola, tal como a observamos, se encontra para além do exercício disciplinar.

Visto que, no cenário institucional, a invisibilidade passa a ser imposta às operações práticas que configuram e marcam a cotidianidade escolar, são estas opacidades que oferecem as condições necessárias ao investimento tático: a invisibilidade imposta neste momento aos praticantes funciona como um artifício favorável a estas operações: o que não pode ser apreendido pelo escópica da maquinaria disciplinar, ou ainda, o que não faz parte dos códigos visuais e não-visuais do dispositivo institucional é então capaz de circular subrepticiamente por entre os lugares próprios, nos interstícios abertos dos cotidianos. E justamente ao se fazer da visibilidade-invisibilidade que lhes é imposta, desta invisibilidade que está aquém de toda visibilidade institucional/disciplinar, os praticantes empreendem suas subversões por esbatimento de luz, em um jogo de claro-escuro, especialmente quando tais contendas se passam no bojo de seu próprio corpo.

Nesse sentido, nos parece tão importante trazer para esta conversa o Queer (DIAS, 2012; PINAR, 2007) como possibilidade de se pensar este corpo estranho, corpo que 
produz estranhamentos nas experiências cotidianas, e que inevitavelmente recusa os ordenamentos funcionais e os assujeitamentos disciplinares assim cristalizados, por exemplo, no cuidado e uso dos uniformes. Ademais, as manifestações do corpo, as práticas de fruição e as identidades sexuais produzem e são produzidas inicialmente na experienciação da diferença, em um inesgotável substrato semiótico.

De acordo com a Teoria Queer, Belidson Dias (2012) ressalta que além das investigações sobre gênero e sexualidade essa teoria transita pela identidade, que, muito embora nossas reflexões não estejam restritas ao plano representacional identitário, entendemos colaborar para reflexão desse artigo, pois permite pensar em multiplicidade [...] de maneira a sugerir novas formas de pensar a cultura, a educação, tecnologia, o conhecimento, o poder e representação (DIAS, 2012, p.51).

Antes, sugerimos que, para além das recodificações do que seria um elemento identitário, o diálogo entre a experiência aqui relatada e nossos referenciais teóricos nos permite trazer para esta escrita os possíveis dos cotidianos, em busca de um corpo Queer, de um currículo Queer e de uma sexualidade Queer (PINAR, 2007), tomando assim a ideia de Queer como uma noção guarda-chuva que abriga tudo o que não cabe nas hierarquias e dicotomias e, ao mesmo tempo, uma premissa desinvisibilizadora, afirmativa das diferenças que, queira-se ou não, estruturam os corpos coletivos.

Como pôde ser visto no relato da professora, a potência estética de seu aluno não simplesmente rompeu com a operação de docilização dos corpos, isto é, as estratégias disciplinares que perfazem o espaço escolar, como também, e principalmente, subverteu componentes estruturais de gênero, mobilizando investimentos culturalmente reguladores e, por conseguinte, todo um rito simbólico de violência: uma estética dos ritos e, quando em pulsão gregrária, uma cerimônia das fantasmagorias sociais. A plástica do seu corpo, na medida em que tornava seu corpo matéria plástica, região com a qual sua manipulação estética seria empreendida, inevitavelmente acionou os referentes de uma sexualidade outra e estranha, uma possível e diferente erótica, que além de desconsiderar os padrões heteronormativos, igualmente deflagra a fragilidade de toda uma ficção, ampla e secular, responsável por conservar a valência hegemônica do falocentrico no Ocidente. É um território de lutas e resistências o que o corpo parece figurar.

Mesmo com suas possibilidades permanentemente amputadas, este corpo queer, igualmente vibrátil, termina por evocar de forma subversiva outras temporalidades pulsionais e, portanto, novas paragens visuais que ensejam o desvelo de diferentes mundos epistêmicos, poéticos e imagéticos. Ainda por ecoar no âmbito do prescrito/institucional, suas ressonâncias urdem os encontros cotidianos onde a escola é reinventada e fruída: as vivências que dai se originam inevitavelmente elucidam em currículo os prazeres e as agruras do ser-coletivo: um currículo vibrátil (VICTORIO FILHO, 2012).

Por fim, sem pretender encerrar definitivamente esta conversa, o discorrer de nossas reflexões intentou esclarecer as operações integralizantes contra as quais, sem perceber seu alcance, o estudante se interpôs em prol de um fruir estético centrado no cuidado com o corpo e com sua presença. Isso, a nosso ver, transcorreu em torno da 
visualidade instaurada pelo uniforme escolar e de uma compreensão tácita acerca dos papeis de gênero legitimados pela cultura ocidental. Nesse sentido, a escritura desta conversa se ocupou de um movimento inverso: a premissa desinvibilizadora que este texto procurou/procura fortalecer, portanto, se propôs a melhor pensar a potência epistêmica que principalmente emerge na interface entre ensino de arte e os espaços/tempos da escola, entre o prescrito e o praticado, como também buscou deixar ver brevemente a partir do relatado da professora as possibilidades criativas/poéticas de que se valem os praticantes nos cotidianos, a despeito das punições e prêmios institucionais.

\section{Referências bibliográficas:}

CERTEAU, M. de. A Invenção do Cotidiano: Artes de Fazer. $3^{\text {a }}$ ed., Petrópolis, RJ: Vozes, 1998.

DELEUZE, G. Foucault. São Paulo: Brasiliense, 2005.

. O que é um Dispositivo. Acessado em: 27/08/2012. Disponível em: http:// www.ufes.br/ppgpsi/files/textos/Deleuze\%20-\%20O\%20que\%20\%C3\%A9\%20um\%20 dispositivo.pdf

DIAS, B. O fazer na educação da cultura visual: as des (truções) de Felipe Sobreiro. In: MARTINS, R; MARTINS, A. (Org.). Interações com visualidades em contextos de ensinar e aprender. Goiânia, UFG/FAV; FUNAPE, 2012.

DUNCUN, P. Visual Culture in the Classroom. Art Education, p. 25-32, mar. 2003.

FOUCAULT, M. A vontade de Saber: História da Sexualidade. Rio de Janeiro, Graal, 1979.

. Vigiar e Punir: nascimento da prisão. Petrópolis, RJ, Vozes, 2004.

MARTINS, R. Educação e poder: deslocamentos perceptivos e conceituais da cultura visual. In: OLIVEIRA, M.; HERNÁNDEZ, F. (Org.). A formação do professor e o ensino das artes visuais. Santa Maria, Ed. UFSM, 2005.

NASCIMENTO, E. A pesquisa em artes e a perspectiva da cultura visual. In: MARTINS, R; TOURINHO, I. (Org.). Processos \& práticas de pesquisa em cultura visual \& educação. Santa Maria, UFSM, 2013.

PINAR, W. Punk'd. In Nelson M. Rodriguez and William F. Pinar (Eds.) Queering Straight Teachers: Discourse and Identity in Education (155-182). New York: Peter Lang, 2007.

PORRES, A. Conversações na aula de cultura visual. In: MARTINS, R; TOURINHO, I. (Org.). Processos \& práticas de pesquisa em cultura visual \& educação. Santa Maria, 
UFSM, 2013.

SILVA, K. N. Criança Calçada, Criança Sadia! : Sobre os uniformes escolares no período de expansão da escola pública paulista (1950/1970). Dissertação de Mestrado, USP, 2006.

VICTORIO FILHO, A. A Arte na/da Educação: a invenção cotidiana da escola. Tese de Doutorado, UERJ, 2005.

. Corpo Escola: currículo vibrátil e pedagogia da carne. In: Revista Currículo sem Fronteiras, v. 12, n. 3, Set/Dez, 2012, p. 143-152. 